INTERNATIONAL JOURNAL OF RESEARCHES IN BIOSCIENCES, AGRICULTURE AND TECHNOLOGY

(C) VISHWASHANTI MULTIPURPOSE SOCIETY (Global Peace Multipurpose Society) R. No. MH-659/13(N) www.vmsindia.org

\title{
THE EFFECTS OF ELECTROMAGNETIC RADIATION IN THE RF SPECTRUM
}

\author{
A. P. Bhat ${ }^{1}$, A. Tiwaria $^{2}$, M. Badar 3 S. S. Darokar ${ }^{4}$, A. Lad ${ }^{5}$, G. Rewatkar 6 \\ ${ }^{1}$ PGTD, RTM Nagpur University, Nagpur \\ 2govt. Bilasa Girls P.G. College Bilaspur (C.G) \\ ${ }^{3}$ Dr. Ambedkar College, Nagpur, 10, India \\ ${ }^{4}$ Shivaji Science College, Nagpur, 10, India \\ ${ }^{5}$ Amlokchand science college, Amravati, 22, India \\ ${ }^{5}$ Dr. Ambedkar College, Nagpur, 10, India \\ anup_b5@yahoo.com
}

\begin{abstract}
:
Electromagnetic (EM) effect measurements in crowded area specifically areas study is under consideration of this paper, and statistical analysis for EM and EM sources causing destructive interference is consider. The measurement and estimated values is the analysed using the statistical analysis in comparative manner. Also, amplitude fluctuations of the electromagnetic radiations from different EM sources were detected for a long time, and statistical analyses were made. EM field levels were measured in RTM Nagpur university campus area where cellular base stations and TV/Radio stations are available with the maximum field power. EM radiation levels were measured for the FM, UHF4, VHF4 and VHF5 stations for certain spectrum ranges under far-field conditions by utilizing isotropic field probe designed using the rectangular loop and virtual spectrum analyzer developed using the LabVIEW software utility. The measurements were fulfilled by using EM Detector with isotropic loop antenna that can be designed and utilized in $75 \mathrm{MHz}-2.3 \mathrm{GHz}$ frequency range. The measurement results for each source were compared, and their contributions to the combined radiation were analyzed.
\end{abstract}

Keywords: RF Spectum, radiation, sepctrum conjuction, LabVIEW

\section{Introduction:}

The potential health effects of EM radiation from the source for broadcasting of radio-TV and mobile communication are the subject of on-going researches [1-4]. Many researches and studies [5-9] about the EM radiation effects of the devices operating especially in GSM bands. The distribution and levels of EM radiation in the crowded residential areas are very important. From the statistical analysis of the measurement results, EM radiation levels can be modelled through various calculations and formulas retrieved under certain conditions and within acceptable correctness. EM radiation measurement results are explained with the help of time dependent series analysis are suitable for predicting future EM radiation levels through the developed model. Estimation or determination of the dependant variable total EM radiation is realized as based on the modelling. EM radiation measurements within the scope of this study were executed in a chosen pilot region as university campus area which have geographical topmost heighted area.

\section{Material and Methods:}

EM radiation measurements are in a particular, populated educational and nearby residential area where EM radiation is expected in wide range of frequency spectrum. EM radiation study carried out with the fact as •
The effects of the transmitting sources when only looking at

the static data. - Reliability of distribution modelling is low, since distribution modelling is based on probability. - it is almost impossible to get and measured up to date information with reliability about the modelling of structures(buildings, greenery, mega obstacle, water ponds, lacks) and other obstructions located in the region. Table 1. Variation of the far field distance according to the frequency of GSM sources.

\section{Result and Discussion:}

During the EM radiation measurements for GSM900 and GSM1800 base stations, the distances in Table 1 are considered. It is assumed that only far field conditions exist since it is not possible to reach closer to these sources as far as these distances. - Same approach is applied to the FM radio transmitters in city centres since those sources are also installed on high buildings in order to provide maximum coverage. $\bullet$ it is assumed that only far field conditions exist for the $\mathrm{TV}$ and $\mathrm{FM}$ radio transmitters - Near field conditions provide more realistic results for measurements in laboratory environment and for a certain source [10]. Table 1 gives the far field starting distances for a $1 \mathrm{~m}$ length antennas and bands GSM900/GSM1800. For the reasons mentioned above, the measurements carried out in order to create the distribution maps were fulfilled based 
on far field conditions in this study. In practice, many of the directional antennas with high gains are not suitable for this purpose since they do not allow measurements of signals from all directions and different polarizations. In the measurements, the wide band spectrum $(75$ $\mathrm{MHz}-2.3 \mathrm{GHz}$ ) antenna probes that can measure from all directions and different polarizations $[11,12]$ is used. E field values were recorded during the measurements. Co-ordinates of each measurement location were also recorded by using a Global Position System (GPS) for mapping process. The measurement locations were decided according to the density of mobile users since it is an important factor [10, 13]. Numbers of measurements for crowded locations were more than other places. The electric field probe was based at $3.3 \mathrm{~m}$ height from the ground level. Measurement device and probe were mounted on the vehicle's insulating ceiling made of no reflective fibre material. The duration of each measurement was 3 minutes $[13,15]$. For each measurement Eave $(\mathrm{V} / \mathrm{m})$ was recorded. Figure 2: Experimental setup Table 2: Measured EM radiation sources and their frequency ranges. EM Source Frequency Range U s e FM $88-108 \mathrm{MHz}$ Local radio stations UHF5 605-861 MHz CT Police link VHF4 174-230 $\mathrm{MHz}$ Base band comm. UHF4 605-861 MHz TVradio link GSM900 870-960 $\mathrm{MHz}$ Mobile freq GSM1800 1.77-1.85 GHz Mobile-data freq

\section{Conclusion:}

This EM radiation measurement study was done with high level of EM radiation expectations based on the cell phone population , constructions, industrial intensity. The study involved quantifies measurements to determine the electromagnetic field levels in and around the university campus area with EM radiation estimations. As shown in Table 4, total radiation value was recorded as average $0.71-0.61 \mathrm{~V} / \mathrm{m}$, and its standard deviation was 0.30 according to the measurement results taken from various locations in campus. GSM1800 average radiation value was calculated as $0.30 \mathrm{~V} / \mathrm{m}$, and its standard deviation was calculated 0.153 . GSM900 average radiation value was $0.42 \mathrm{~V} / \mathrm{m}$, and its standard deviation was calculated 0.355 . GSM900 average radiation value was found being the highest correlation relation of 0814 with total EM radiation value. GSM1800 average radiation value was found 0.364 correlation relation with total value. In other words, total EM radiation is affected by $81.4 \%$ due to variation in radiation of GSM900 and by $36.4 \%$ for GSM 1800.

\section{Acknowledgement:}

The author would like to thank to Department of Electronics RTM Nagpur University Nagpur and Department of Statistics Dr. Ambedkar College Nagpur for providing the necessary help and support.
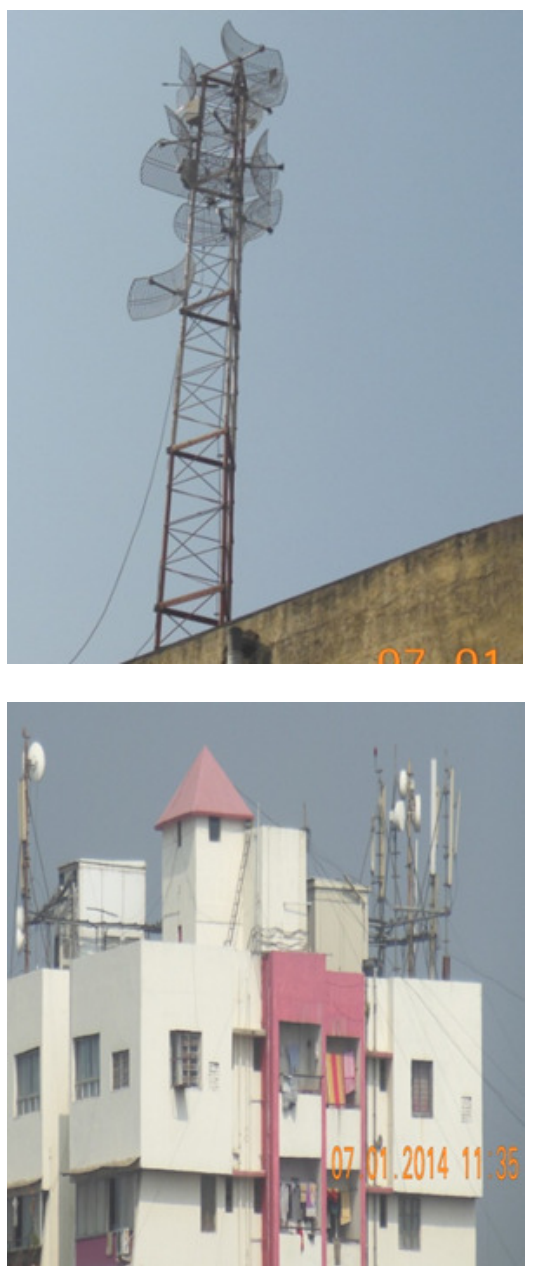

Figure:1. Some EM radiation sources in the measurement areas.

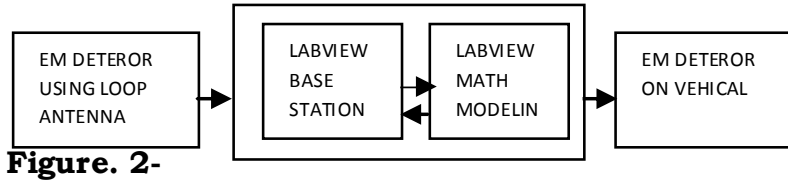

\section{References:}

1. Wu, B. I., F. C. A. I. Cox, A. Kong, "Experimental methodology for non-thermal effects of electromagnetic radiation on biologics,"Journal of Electromagnetic Waves and Applications, Vol. 21, No. 4, 533-548, 2007.

2. Kuo, L. C., Y. C. Kan, H. R. Chuang, "Analysis of a $900 / 1800-\mathrm{MHz}$ dual-band gap loop antenna on a handset with proximate head and hand model," Journal of Electromagnetic Waves and Applications, 21(1),107-122, 2007.

3. Giliberti, C.,F, Boella, A. Bedini, R. Palomba, L. Giuliani, "Electromagnetic mapping of urban areas: The example of 
monselice (Italy)," PIERS Online, 5( 1), 56-60, 2009.

4. Mahmoud, K. R., M. E1-Adawy, S. M. M. Ibrahem, R. Bansal, S. H. Zainud-Deen, "Investigating the interaction between a human head and a smart handset for $4 \mathrm{G}$ mobile communication systems," Progress In Electromagnetic Research C, 2, 169- 188, 2008

5. Zygiridis, T. T.,T. D. Tsiboukis, "Assessment of human head exposure to wireless communication devices: Combined electromagnetic and thermal studies for diverse frequency bands," Progress In Electromagnetics Research B, 9, 83-96, 2008.

6. Islam, M. T.,M. R. I. Faruque, N. Misran, "Reduction of specific absorption rate (SAR) in the human head with ferrite material and metamaterial," Progress In Electromagnetics Research C, 9, 47-58, 2009.

7. Forigo, D., P. Gianola, R. Scotti, and R. Vallauri, "Measurements and numerical evaluation of the electric field in the near-zone of radio base station antennas," Antennas and Propagation Society

8. Manapati, M. B. and R. S. Kshetrimayum, "SAR reduction in human head from mobile phone radiation using single negative metamaterials," Journal of Electromagnetic Waves and Applications, 23(10), 1385-1395, 2009.

9. Ozdemir, A. R., "Radio frequency electromagnetic fields levels in urban areas of Istanbul, Ankara and Izmir and protection techniques," Thesis for Expertise,
Telecommunication Society Publications, Ankara, Turkey, 2004.

10. Shachar, A., R. Hareuveny, M. Margaliot, and G. Shani, "Measurements and analysis of environmental radio frequency electromagnetic radiation in various locations in Israel," Soreq Nuclear Research Center, Israel, 2004.

11. Voudouris, K. and P. Grammatikakis, "Radiation measurements at short wave antenna park," Proceedings of the 4th WSEAS In- ternational Conference on Telecommunications and Informatics, 48, Prague, Czech Republic, 2005.

12. Hamid, R., M. Cetintas, H. Karacadag, A. Gedik, M. Yogun, and M. Celik, "Measurement of electromagnetic radiation from GSM base stations," IEEE International Symposium on EMC, TUBITAK-UME, Gebze, Turkey, 2003.

13. Getsov, P., D. ,Teodosiev, E. Roumenina, M. Israel, G. Mardirossian, G. Sotirov, B. Srebrov, "Methods for monitoring electromagnetic radiation in the Western Balkan environment," SENS 2007 Third Scientific Conference with International Participation Space, Ecology, Nanotechnology, Safety, Varna, Bulgaria, 2007.

14. Gujarati, D., Basic Econometrics, Literature Publishing, Turkey, 2001.

15. Sevuktekin, M. and M. Nargelecekenler, Time Series Analysis, 1st Edition, Nobel Publishing, Turkey, 2005.

16. Emec, H., "Time series econometric I: Stability, unit roots," IIBF, Dokuz Eylul University, Izmir, Turkey, 2007. 